\title{
Synthesis and evaluation of mucoadhesive acryloyl-quaternized PDMAEMA nanogels for ocular drug delivery
}

Article

Accepted Version

Creative Commons: Attribution-Noncommercial-No Derivative Works 4.0

Brannigan, R. P. and Khutoryanskiy, V. V. (2017) Synthesis and evaluation of mucoadhesive acryloyl-quaternized PDMAEMA nanogels for ocular drug delivery. Colloids and Surfaces B: Biointerfaces, 155. pp. 538-543. ISSN 0927-7765 doi: https://doi.org/10.1016/j.colsurfb.2017.04.050 Available at https://centaur.reading.ac.uk/70302/

It is advisable to refer to the publisher's version if you intend to cite from the work. See Guidance on citing.

Published version at: http://www.sciencedirect.com/science/article/pii/S0927776517302369

To link to this article DOI: http://dx.doi.org/10.1016/j.colsurfb.2017.04.050

Publisher: Elsevier

All outputs in CentAUR are protected by Intellectual Property Rights law, including copyright law. Copyright and IPR is retained by the creators or other copyright holders. Terms and conditions for use of this material are defined in the End User Agreement.

www.reading.ac.uk/centaur 
Central Archive at the University of Reading

Reading's research outputs online 


\section{Synthesis and evaluation of mucoadhesive acryloyl-quaternized PDMAEMA nanogels for ocular drug delivery}

Ruairi P. Brannigan, Vitaliy V. Khutoryanskiy*.

*School of Pharmacy, University of Reading, Reading, RG6 6UR, UK.

KEYWORDS: Mucoadhesion, nanogels, quaternization, PDMAEMA, ocular drug delivery ABSTRACT: Poly((2-dimethylamino)ethyl methacrylate) (PDMAEMA) nanogels were synthesized via surfactant-free free-radical polymerization technique in aqueous conditions utilizing $N, N^{\prime}$-methylene-bis-acrylamide (MBA) as a crosslinking agent. The PDMAEMA nanogels were subsequently quaternized with acryloyl chloride in order to yield mucoadhesive materials which incorporate two mucoadhesive concepts; electrostatic interactions and covalent bond forming acrylate groups. The native PDMAEMA nanogels were found to exhibit good mucoadhesive properties on ex vivo bovine conjunctival tissues, which was found to increase proportionally with the degree of quaternization. With a view to determine the ocular drug delivery capabilities of the materials, both quaternized and native nanogels were loaded with pilocarpine hydrochloride via an absorption method, and their in vitro release profiles were analysed. The nanogels were found to exhibit a high loading capacity ( $>20 \%$ of total weight) and a sustained release over 6 hours.

Total number of words: 3825

Tables: 2

Figures: 4

Scheme: 1 


\section{INTRODUCTION:}

Mucoadhesive materials are defined as materials which exhibit an attractive interaction, or adherence, at the interface between the material and the mucosal gel layer of a mucosal membrane. ${ }^{1}$ Mucosal membranes are moist tissue linings which envelop all cavities and canals which communicate with the exterior i.e. genitourinary tract, respiratory passages, aural and ocular passages, etc. ${ }^{2}$ Mucoadhesive materials have received a substantial attention from pharmaceutical sectors in recent decades owing to their unprecedented ability to act as drug delivery systems to mucosa, increasing the residence times of therapeutic agents at the site of delivery. ${ }^{3-5}$

Since the inception of mucoadhesion as a drug delivery mechanism, a plethora of polymeric materials have been shown to exhibit mucoadhesive capabilities, however these materials avail of a limited number of transient attractive interactions e.g. hydrophobic interactions, Van der Waals forces, hydrogen bonding and ionic interactions. ${ }^{6,7}$ More recently, efforts have been made to improve the mucoadhesive properties of polymeric materials through the addition of covalent bond forming groups i.e. thiols, maleimides, catechols, etc. ${ }^{8-11}$ In the past decade, there has been some interest in the utilization of acrylated polymers as covalent bond forming mucoadhesive functionalities. ${ }^{12}$ First reported in 2010, acrylated polymers exhibit mucoadhesive properties as a consequence of their ability to undergo a Michael-type reaction with thiol/sulfide groups present in the cysteine-rich termini of the mucin glycoproteins at the mucosal surface. ${ }^{13}$

An area which has gained a substantial attention in the field of mucosal drug delivery recently, is the utilization of nanogel systems. Nanogels are defined as nanosized particles composed of a physically or chemically crosslinked polymer network which exhibits the ability to swell when in a 'good' solvent, typically water. ${ }^{14}$ Nanogels offer a unique platform for mucosal drug delivery 
they can facilitate high drug loading capacities in addition to exhibiting excellent biocompatibility, enhanced colloidal stability and large surface areas with tunable chemical and physical properties. $^{15-17}$

Herein, we describe the synthesis of crosslinked poly((2-dimethylamino)ethyl methacrylate) (PDMAEMA) nanogels and the subsequent quaternization with acryloyl chloride yielding mucoadhesive nanogels which incorporate two mucoadhesive concepts; electrostatic interactions with negatively-charged mucins and covalent bond formation between acrylated moieties and thiol-groups present in cysteine-rich fragments of mucins. These dual-functional materials were analyzed to determine their mucoadhesive properties, drug loading capacities and in vitro release profiles. To our knowledge, the utilization of acryloyl chloride in the quaternization of tertiary amines to yield 'dual-functional' mucoadhesive nanogels has never been reported before.

\section{EXPERIMENTAL}

\section{Materials and methods}

Poly(vinyl pyrrolidone) (PVP) $\left(M_{\mathrm{w}}=10,000 \mathrm{~g} \cdot \mathrm{mol}^{-1}\right)$, azobisisobutyronitrile (AIBN), methanol and N,N'-methylene-bis-acrylamide were purchased from Sigma Aldrich. Acryloyl chloride and $N, N$-dimethylaminoethyl methacrylate (DMAEMA) were purchased from Alfa Aesar (Lancashire, United Kingdom). Dialysis membranes $\left(M_{\mathrm{w}}\right.$ cut-off $\left.=12-14 \mathrm{kDa}\right)$ were purchased from Medicell International Ltd (London, United Kingdom). All reagents were used as received unless otherwise stated. ${ }^{1} \mathrm{H}$ nuclear magnetic resonance (NMR) spectra were recorded on a Bruker Ultrasheild 400 plus NMR spectrometer at $298 \mathrm{~K}$. All chemical shifts were reported as $\delta$, in parts per million (ppm) and referenced against the chemical shift of residual solvent resonances (DMSO: $\delta=2.50 \mathrm{ppm}$ ). Fourier transform infrared (FT-IR) spectra were 
recorded using a Perkin Elmer spectrum 100 infrared spectrophotometer at a wave number range of 500-4000 $\mathrm{cm}^{-1}$. Thermogravimetric analysis (TGA) was conducted on TGA Q50 and the data was subsequently analysed using TA universal analysis software. Samples were placed in aluminium crucibles and were subject to a heating rate of $10{ }^{\circ} \mathrm{C} \cdot \mathrm{min}^{-1}$ from $25{ }^{\circ} \mathrm{C}$ to $500{ }^{\circ} \mathrm{C}$, under a nitrogen atmosphere. The z-average hydrodynamic diameter, polydispersity (PDI) and zeta-potential were determined using a Nano Zetasizer at $25^{\circ} \mathrm{C}$. Samples for z-average and PDI determination were made to a concentration of $0.1 \mathrm{mg} \cdot \mathrm{mL}^{-1}$ in deionized $\mathrm{H}_{2} \mathrm{O}$. Samples for zetapotential determination were made according to literature $\left(0.25 \mathrm{mg} \cdot \mathrm{mL}^{-1}\right.$ of $0.005 \mathrm{M} \mathrm{NaCl}$ aqueous solution) and conducted in a disposable folded capillary cell. ${ }^{24}$ Transmission electron microscopy (TEM) was performed on a $200 \mathrm{kV}$ Philips CM 20 TEM microscope. Samples were transferred onto a carbon-coated copper grid and subsequently stained with uranyl acetate. Bovine eyeballs were obtained from a local abattoir on the day of slaughter, and transported in phosphate buffer $(\mathrm{pH} 7.4)$ maintained at $4-8{ }^{\circ} \mathrm{C}$. The conjunctival tissues were removed and washed using phosphate buffer and used within $24 \mathrm{~h}$ of dissection. Fluorescence images were taken using a Leica MZ10F fluorescence stereomicroscope fitted with a GFP filter and subsequently analysed using ImageJ software. Simulated tear fluid was composed of $\mathrm{NaCl}$ (6.7 g), $\mathrm{NaHCO}_{3}(2.0 \mathrm{~g}), \mathrm{CaCl}_{2} \cdot 2 \mathrm{H}_{2} \mathrm{O}(0.08 \mathrm{~g})$ dissolved in $1000 \mathrm{~mL}$ of deionized water. ${ }^{18}$ Unless stated otherwise, all experiments were repeated 3 times and the data presented as mean \pm standard deviation. The statistical significance of the differences in retention experiments was examined using a two-way ANOVA statistical analysis, performed on GraphPad Prism v5.0 using Tukey's post hoc test, where $\mathrm{p}<0.05$ was considered to be statistically significant. 


\section{Synthesis of quaternized PDMAEMA nanogels}

Poly(N,N-dimethylaminoethyl methacrylate) (PDMAEMA) nanogels were synthesized via a method modified from a previous study. ${ }^{19}$ In a clean dry round-bottom flask (RBF) fitted with a stirrer bar, septum and nitrogen flush, DMAEMA (1.6 g, $10.18 \mathrm{mmol})$, MBA (8 mg, $5.19 \times 10^{-2}$ $\mathrm{mmol})$ and AIBN (4 mg, $\left.2.43 \times 10^{-2} \mathrm{mmol}\right)$ were dissolved in $2 \mathrm{~mL}$ of ethanol with stirring (100 rpm) before the addition of $18 \mathrm{~mL}$ of deionized $\mathrm{H}_{2} \mathrm{O}$ and PVP as an emulsifying agent (160 mg, $\left.1.60 \times 10^{-2} \mathrm{mmol}\right)$. The polymerization solution was allowed to equilibrate for 10 min under a nitrogen purge before being heated to $70{ }^{\circ} \mathrm{C}$ for $2 \mathrm{~h}$. After the polymerization was completed, the reaction solution was transferred to a dialysis membrane and dialyzed against deionized $\mathrm{H}_{2} \mathrm{O}$ (4L deionized $\mathrm{H}_{2} \mathrm{O}$ for 5 days changing the dialysis media twice daily), yielding a cloudy nanogel suspension $\left(16 \mathrm{mg} \cdot \mathrm{mL}^{-1}\right.$ in deionized $\left.\mathrm{H}_{2} \mathrm{O}\right)$. PDMAEMA nanogels were stored at $4-8{ }^{\circ} \mathrm{C}$ and were lyophilized prior to ${ }^{1} \mathrm{H}$ NMR and FT-IR spectroscopic analysis. ${ }^{1} \mathrm{H}$ NMR (400 MHz, $\left.\mathrm{D}_{2} \mathrm{O}\right)$ $\delta$ 4.45-3.95 (m, 2H, $\left.-\mathrm{CH}_{2}-\mathrm{N}\left(\mathrm{CH}_{3}\right)_{2}\right), 3.34\left(\mathrm{~m}, 2 \mathrm{H},-\mathrm{C}(\mathrm{O}) \mathrm{O}-\mathrm{CH}_{2}-\right), 2.89\left(\mathrm{~m}, 6 \mathrm{H}, \mathrm{CH}_{2}-\mathrm{N}\left(\mathrm{CH}_{3}\right)_{2}\right)$, 1.87-1.11 (m, 5H, $\left.-\mathrm{CH}_{2}-\mathrm{C}\left(\mathrm{CH}_{3}\right)-\right)$.

In a clean dry glass vial fitted with a stirrer bar and nitrogen flow, $10 \mathrm{~mL}$ of the PDMEAMA nanogel solution was cooled using a salt water ice-bath before the dropwise addition of acryloyl chloride ( $40 \%$ quaternization $=2 \mathrm{~mL}, 24.62 \times 10^{-2} \mathrm{mmol}, 18 \%$ quaternization $=1 \mathrm{~mL}, 12.31 \times 10^{-2} \mathrm{mmol}, 8 \%$ quaternization $\left.=0.5 \mathrm{~mL}, 6.16 \times 10^{-2} \mathrm{mmol}\right)$ with vigorous stirring. The reaction was allowed to proceed for $20 \mathrm{~min}$ before being warmed to room temperature with gentle stirring for a further $12 \mathrm{~h}$. Quaternized PDMAEMA nanogels (qPDMAEMA) were subsequently purified by dialysis against deionized $\mathrm{H}_{2} \mathrm{O}$ to yield a slightly opaque nanogel solution $\left(12 \mathrm{mg} \cdot \mathrm{mL}^{-1}\right.$ in deionized $\mathrm{H}_{2} \mathrm{O}$ ). Quaternized PDMAEMA nanogels were stored in dark conditions at $4-8{ }^{\circ} \mathrm{C}$ under nitrogen and were lyophilized prior to ${ }^{1} \mathrm{H}$ NMR 
and FT-IR spectroscopic analysis. ${ }^{1} \mathrm{H}$ NMR (400 MHz, D2O) $\delta 5.99\left(\mathrm{~m}, 3 \mathrm{H},-\mathrm{C}(\mathrm{O}) \mathrm{O}-\mathrm{CH}=\mathrm{CH}_{2}\right)$, 4.27-3.70 (m, 2H, - $\left.\mathrm{CH}_{2}-\mathrm{N}\left(\mathrm{CH}_{3}\right)_{2}\right), 3.29\left(\mathrm{~m}, 2 \mathrm{H},-\mathrm{C}(\mathrm{O}) \mathrm{O}-\mathrm{CH}_{2}-\right), 2.98\left(\mathrm{~m}, 6 \mathrm{H}, \mathrm{CH}_{2}-\mathrm{N}\left(\mathrm{CH}_{3}\right)_{2}\right)$, $1.68-0.91\left(\mathrm{~m}, 5 \mathrm{H},-\mathrm{CH}_{2}-\mathrm{C}\left(\mathrm{CH}_{3}\right)-\right)$.

Retention of PDMAEMA and qPDMAEMA nanogels on ex vivo bovine conjunctival tissue

In order to determine the mucoadhesive properties of PDMAEMA and qPDMAEMA nanogels on ex vivo bovine conjunctival tissue, a modified in-house method previously developed by the group was employed (Scheme S1 ESI $\dagger$ ). ${ }^{20}$ To an aqueous solution of fluorescein sodium (1 $\mathrm{mg} \cdot \mathrm{mL}^{-1}$ in deionized $\mathrm{H}_{2} \mathrm{O}$ ), $10 \mathrm{mg}$ of freshly lyophilized nanogels were added. The fluorescently loaded nanogels were retrieved by centrifugation (13000 rpm) before being reconstituted in $1 \mathrm{~mL}$ of deionized $\mathrm{H}_{2} \mathrm{O}$. To freshly dissected bovine conjunctival tissue $(5 \times 5$ $\mathrm{cm}^{2}$ ), $20 \mu \mathrm{L}$ of the fluorescent nanogels were deposited before being transferred to a slopped channel, incubated at $35^{\circ} \mathrm{C}$, and subsequently washed with simulated tear fluid $\left(500 \mu \mathrm{L} \cdot \mathrm{min}^{-1}\right)$. At pre-determined intervals, fluorescence images were taken of the conjunctival tissue and analyzed for pixel intensity using ImageJ software. The data obtained was presented as a percentage of nanogel remaining on the conjunctival tissue based on the original pixel intensity.

Loading and in vitro release of pilocarpine hydrochloride from PDMAEMA and qPDMAEMA nanogels

Using sacrificial samples for each time-point, freshly lyophilized nanogels (12 mg) were rehydrated in $1 \mathrm{~mL}$ of a $0.5 \%$ aqueous solution of pilocarpine $\mathrm{HCl}$ with gentle stirring. At predetermined time-points, nanogels were removed by centrifugation and washed with $1 \mathrm{~mL}$ aliquots of deionized water $(\times 2)$, by repeated resuspension and centrifugation. Aqueous washings 
were combined with the supernatant liquid, lyophilized and reconstituted to $1 \mathrm{~mL}$ before being filtered $(0.45 \mu \mathrm{m}$ syringe filter) and analyzed by UV-vis spectrophotometry $(\lambda=220 \mathrm{~nm})$ in order to determine the active pharmaceutical ingredient (API) not adsorbed into the nanogel matrix. The in vitro release of pilocarpine $\cdot \mathrm{HCl}$ was conducted using a modified method outlined by Vong et $a l .{ }^{21}$ Using sacrificial samples; $25 \mathrm{mg}$ of loaded nanogels were suspended in $10 \mathrm{~mL}$ of simulated tear fluid and incubated at $35^{\circ} \mathrm{C}$ with gentle agitation $(30 \mathrm{rpm})$. At predetermined time-points, nanogels were removed by centrifugation and the supernatant fluid was collected and passed through a $0.45 \mu \mathrm{m}$ syringe filter before being analyzed by UV-vis spectrophotometry. For both loading and release studies, results were reported as a percentage of pilocarpine $\cdot \mathrm{HCl}$ adsorbed and released based on the original quantity of drug in solution.

\section{RESULTS AND DISCUSSION}

Synthesis of quaternized PDMAEMA nanogels

Scheme 1. Synthesis of quaternized PDMAEMA nanogels ${ }^{a}$

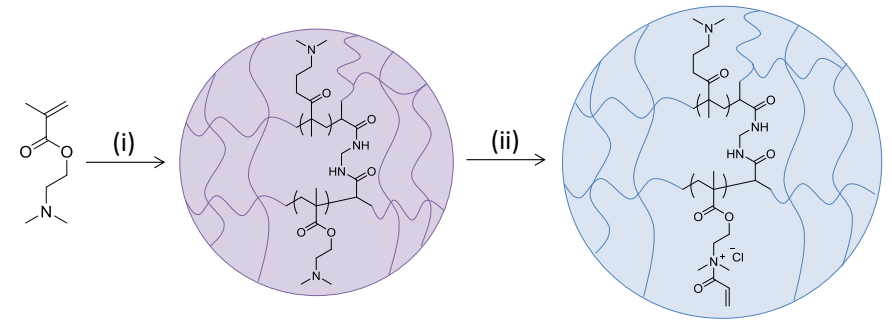

aReagents and conditions: (i) $\mathrm{H}_{2} \mathrm{O}$ :EtOH, DMAEMA, MBA, PVP, AIBN, $70{ }^{\circ} \mathrm{C}, 2 \mathrm{~h}$ (ii) Acryloyl chloride, $0-25^{\circ} \mathrm{C}, 12 \mathrm{~h}$.

The successful synthesis of the nanogels, and post-polymerisation modification, was confirmed by ${ }^{1} \mathrm{H}$ NMR and FT-IR spectroscopy. In agreement with the literature, the ${ }^{1} \mathrm{H}$ NMR spectrum 
exhibited characteristic peaks at $2.89,4.32,3.42$ and $2.10-0.65 \mathrm{ppm}$, attributed to the $-\mathrm{CH}_{3} \neg$ protons of the dimethylamino- functionality, the ethyl side-chain, and the hydrocarbon backbone, respectively (Fig. 1). The FT-IR spectrum further confirms the synthesis of the crosslinked PDMAEMA nanogels via the presence of absorbance bands which are attributed to the carbonyl functionality of the PDMEAMA $\left(1735 \mathrm{~cm}^{-1}\right)$ and MBA crosslinking agent $\left(1645 \mathrm{~cm}^{-1}\right)$. Additionally, an absorbance band ascribed to the tertiary dimethylamino- functionality is present at $1140 \mathrm{~cm}^{-1}$ (Fig. S1). The tertiary amino- functional groups of PDMAEMA were modified post polymerization by the direct addition of acryloyl chloride to the nanogel suspension at reduced temperatures. The successful quaternization of the PDMAEMA nanogels (qPDMAEMA) was confirmed via ${ }^{1} \mathrm{H}$ NMR spectroscopy through a characteristic shift of the methyl protons from $2.89 \mathrm{ppm}$ to $2.98 \mathrm{ppm}$, in combination with the appearance of a multiplet between 5.98-6.44 ppm attributed to the alkene functional group of the acryloyl chloride.

Table 1. Synthesis of quaternized PDMAEMA nanogels.

\begin{tabular}{|c|c|c|c|}
\hline Nanogel & $\begin{array}{l}\text { Acryloyl chloride } \\
\text { (mL) }\end{array}$ & $\begin{array}{l}\text { Degree of } \\
\text { quaternization } \\
(\%)\end{array}$ & $\begin{array}{l}\text { Yield } \\
(\%)\end{array}$ \\
\hline PDMAEMA & 0 & 0 & 69 \\
\hline qP8 & 0.5 & 8 & 57 \\
\hline qP18 & 1.0 & 18 & 60 \\
\hline qP40 & 2.0 & 40 & 54 \\
\hline
\end{tabular}

${ }^{a}$ Determined by ${ }^{1} \mathrm{H}$ NMR spectroscopy ( $\left.\mathrm{D}_{2} \mathrm{O}, 400 \mathrm{MHz}, 298 \mathrm{~K}\right)$. 


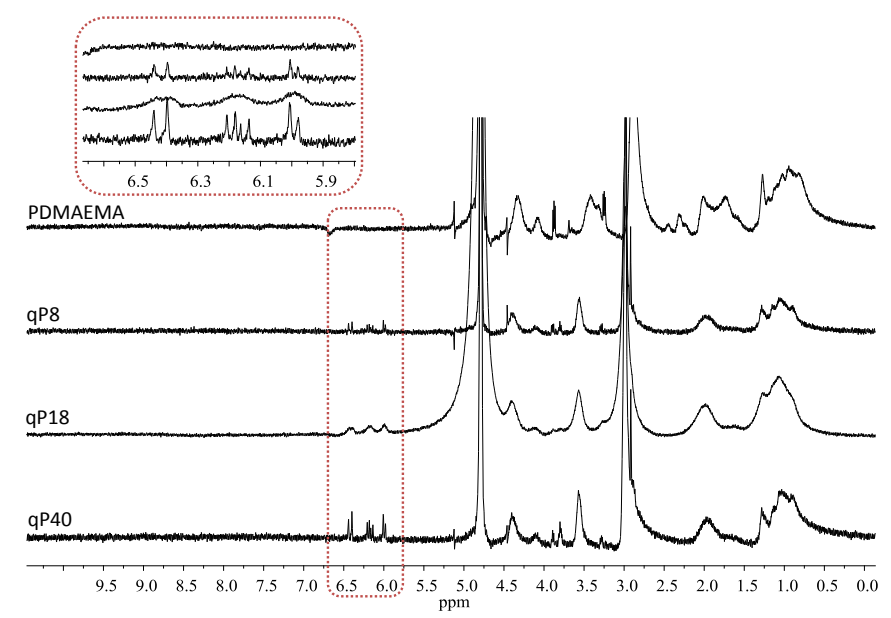

Figure 1. ${ }^{1} \mathrm{H}$ NMR spectra of native and quaternized PDMAEMA nanogels $\left(\mathrm{D}_{2} \mathrm{O}, 400 \mathrm{MHz}, 298\right.$ K).

Additionally, the FT-IR spectra exhibit the evolution of an absorbance band at $2630 \mathrm{~cm}^{-1}$ associated with the presence of a quaternary amine with a chloride counter-ion whilst retaining the PDMAEMA functionalities. Interestingly it was found that by varying the quantity of acryloyl chloride used during post-polymerization modification, the degree of quaternization could be modulated. The degree of quaternization was determined by ${ }^{1} \mathrm{H}$ NMR spectroscopy, using the integration ratio of dimethylamine protons to acryloyl protons (Fig. 1, Table 1). Furthermore, the thermogravimetric analysis (TGA) of the native PDMAEMA revealed the presence of a single inflection at $370{ }^{\circ} \mathrm{C}$ relating to the degradation of the polymer matrix, however, qP40 quaternized nanogel exhibited an initial loss of mass between $125-370{ }^{\circ} \mathrm{C}$ before complete degradation of the polymer matrix, attributed to the degradation and loss of the quaternized acryloyl group (Fig. S2). 


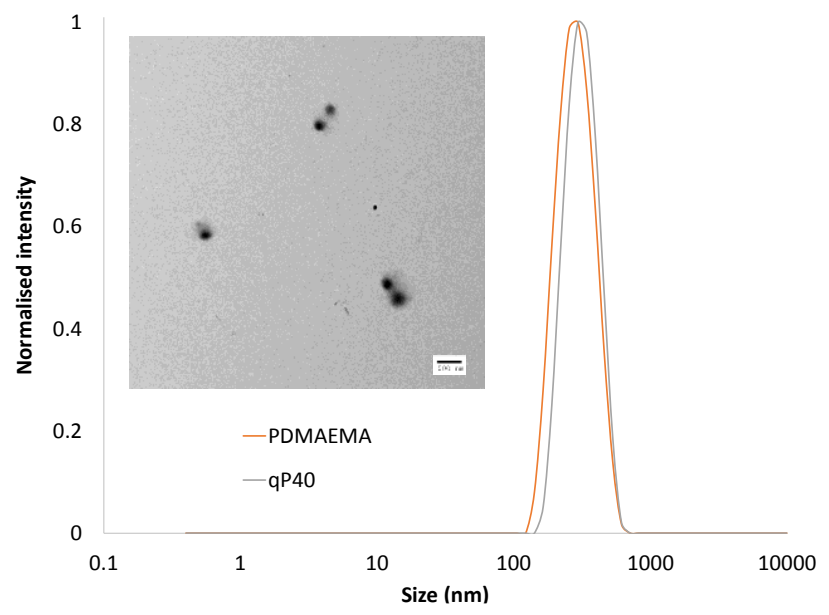

Figure 2. Hydrodynamic diameter of native PDMAEMA and 40\% quaternized nanogels, as determined by dynamic light scattering. Inserted image: TEM image of the qP40 nanogel (Scale bar $100 \mathrm{~nm})$.

Table 2. Physicochemical features of native PDMAEMA and quaternized nanogels.

\begin{tabular}{|c|c|c|c|c|}
\hline Nanogel & $\begin{array}{l}\text { Degree of } \\
\text { quaternization }^{\text {a }} \\
(\%)\end{array}$ & $\begin{array}{l}\text { Z-average } \text { b* }^{*} \\
(\mathrm{~nm})\end{array}$ & $\mathbf{P D I}^{\mathbf{b}^{*}}$ & $\begin{array}{l}\text { Zeta potential }{ }^{b^{* *}} \\
(\mathrm{mV})\end{array}$ \\
\hline PDMAEMA & 0 & $278 \pm 2$ & 0.143 & $25.6 \pm 0.1$ \\
\hline qP8 & 8 & $296 \pm 3$ & 0.149 & $28.9 \pm 0.2$ \\
\hline qP18 & 18 & $311 \pm 2$ & 0.144 & $32.3 \pm 0.3$ \\
\hline qP40 & 40 & $331 \pm 3$ & 0.143 & $33.8 \pm 0.4$ \\
\hline
\end{tabular}

a Determined by ${ }^{1} \mathrm{H}$ NMR spectroscopy $\left(\mathrm{D}_{2} \mathrm{O}, 400 \mathrm{MHz}, 298 \mathrm{~K}\right) .{ }^{\mathrm{b}}$ Determined by dynamic light scattering (DLS) (Nano Zetasizer, $\left.25^{\circ} \mathrm{C}\right) .{ }^{*} 0.1 \mathrm{mg} \cdot \mathrm{mL}^{-1}$ in deionized $\mathrm{H}_{2} \mathrm{O} .{ }^{* *} 0.25 \mathrm{mg} \cdot \mathrm{mL}^{-1}$ of $0.005 \mathrm{M} \mathrm{NaCl}$ aqueous solution. 
The size and shape of the PDMAEMA nanogels, and their post-polymerization modified analogues, were confirmed using dynamic light scattering (DLS) analysis and transmission electron microscopy (TEM). It was found that the unmodified PDMAEMA nanogels exhibited a unimodal size distribution with reasonable polydispersities (PDI $<0.2$, Table 2 ), with a z-average of $278 \pm 2 \mathrm{~nm}$. Furthermore, in agreement with literature, the PDMAEMA nanogels exhibited

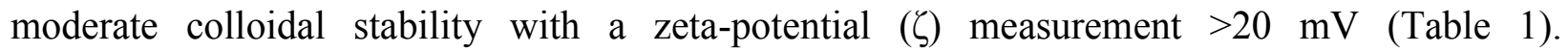
Interestingly, after modification with acryloyl chloride, it was found that both the z-average and $\zeta$-potential increased proportionally to quaternization, whereas PDI was found to decrease after an initial increase (Table 2). This is a consequence of an increase in hydrophilicity with quaternization, leading to the nanogels swelling and increasing in colloidal stability. It was noted that of both the quaternized and native PDMAEMA nanogels exhibited a spherical nature by TEM in addition to a decrease in size as a consequence of dehydration.

\section{Retention of PDMAEMA and qPDMAEMA nanogels on ex vivo bovine conjunctival tissue}

In a study by Keely et al., linear PDMAEMA-based materials were found to exhibit excellent mucoadhesive properties on both isolated rat intestinal sacs and human mucus-producing E12 monolayers. Furthermore, the PDMAEMA-based materials were found to exhibit a minimal cytotoxic effect. ${ }^{22}$ More recently, Long et al. showed that quaternized polymeric amines showed no significant cytotoxicity up to $25 \mathrm{~mol} \%{ }^{23}$ These studies offered a reputable precedent for the synthesis and application of acryloyl chloride quaternized PDMAEMA nanogels for mucoadhesion to ocular conjunctive tissues.

Utilizing an in-house method previously developed by the group, the mucoadhesive properties of PDMAEMA and quaternized PDMAEMA nanogels on ex vivo bovine conjunctival tissue 
were determined (Scheme S1, Fig S3). In order to allow for viable experimental times, the rate of conjunctival tissue washing with simulated tear fluid was two orders of magnitude greater than natural tear production $\left(2 \mu \mathrm{L} \cdot \mathrm{min}^{-1}\right)$. Complementary to previous studies of PDMAEMA-based materials, the native PDMAEMA nanogels offered a good degree mucoadhesion with $>60 \%$ retention after 60 min of continuous washing (Fig. 3). This is a consequence of the inherent cationic nature of PDMAEMA interacting with sialic/sulfuric acid residues of the mucin glycoproteins.

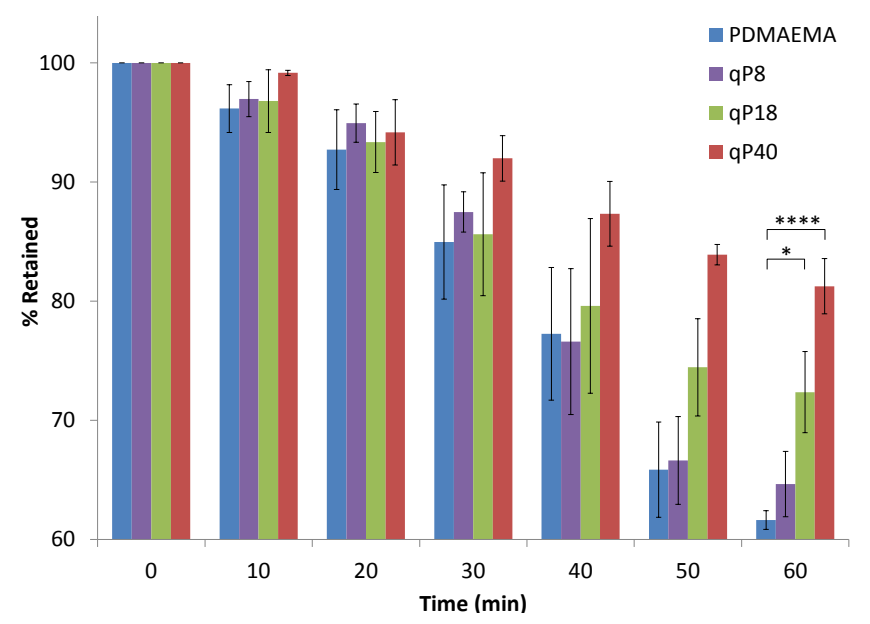

Figure 3. Percentage retention of PDMAEMA and quaternized PDMAEMA nanogels on ex vivo bovine conjunctival tissue. Data expressed as mean \pm standard deviation $(n=3)$. *Statistically significant difference $(\mathrm{P}<0.05) . * * * *$ Statistically significant $(\mathrm{P}<0.0001)$.

It was found that once quaternized; the qPDMAEMA nanogels exhibited an increase in retention on the mucosal surface. Furthermore, it was noted that the percentage retained increased proportionally with the degree of quaternization, with $8 \%$ quaternization exhibiting $\approx$ $65 \%$ retention, $18 \%$ quaternization exhibiting $\approx 70 \%$ retention and $40 \%$ quaternization exhibiting 
$\approx 80 \%$ retention after 60 min washing. A statistical two-way analysis of variance (ANOVA) was conducted on the retention data and it was found that the enhanced final retention of both $18 \%$ and $40 \%$ quaternized nanogels were statistically significant when compared to the native PDMAEMA materials. This enhancement of the mucoadhesive properties after quaternization is attributed to both an increase in the zeta-potential (Table 1), which relates to the positive surface charge of the nanogels, and the formation of covalent bonds between the acryloyl functionality and thiol-bearing cysteine residues present on the surface termini of the mucin glycoproteins.

Loading and in vitro release of pilocarpine hydrochloride from PDMAEMA and qPDMAEMA nanogels

In order to demonstrate the capabilities of the PDMAEMA and qPDMAEMA nanogels as potential drug delivery systems for ocular drug delivery, pilocarpine hydrochloride was loaded into the native PDMAEMA and 40\% quaternized PDMAEMA nanogels, as they exhibited the greatest statistical difference in their mucoadhesive properties. This was achieved using a simple adsorption method via rehydration of freeze-dried nanogels in a $0.5 \% \mathrm{w} / \mathrm{v}$ aqueous solution of pilocarpine $\cdot \mathrm{HCl}$. It was found that both the PDMAEMA and quaternized PDMAEMA nanogels exhibited a loading efficiency $89 \%$ and $81 \%$, respectively. Furthermore, PDMAEMA nanogels exhibited maximum loading capacity of $22.3 \%$ of the total weight $\left(297 \mu \mathrm{g} \cdot \mathrm{mg}^{-1}\right.$ nanogel $)$ while qP40 nanogels exhibited a maximum loading capacity of $20.3 \%$ of the total weight $\left(270 \mu \mathrm{g} \cdot \mathrm{mg}^{-1}\right.$ nanogel) (Fig S4). This process was employed to yield loaded nanogels which were subsequently used to determine the in vitro release profile of the nanogels. 


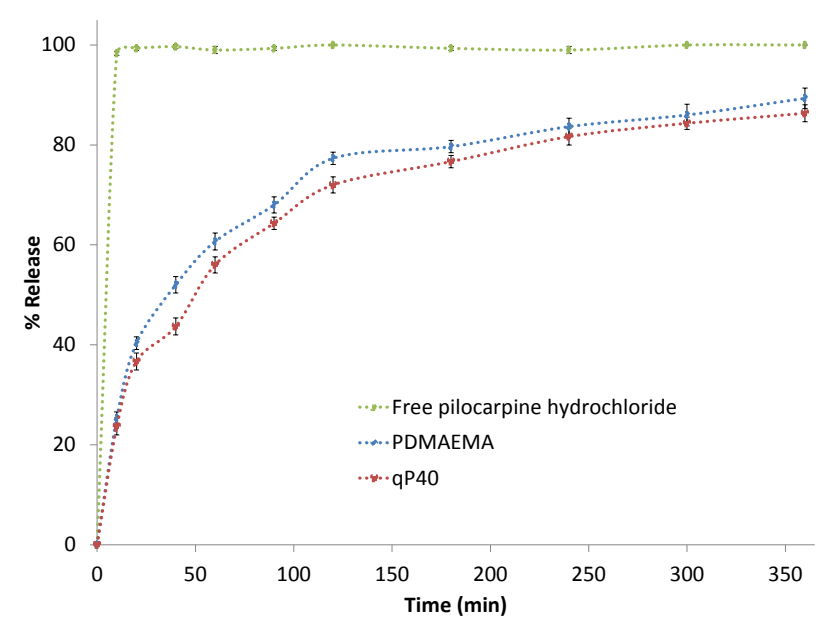

Figure 4. Release profiles of pilocarpine hydrochloride from PDMAEMA and qP40 nanogels. Data expressed as mean standard deviation $(n=3)$.

As suspected, the release profiles of both nanogels exhibited a large burst release $(>50 \%)$ of the API within the first hour. This burst release was followed by a sustained release over the subsequent 5 hours, with a maximum API release between $85-90 \%$ (Fig. 4). This initial burst release is attributed to a combination of surface absorbed pilocarpine $\cdot \mathrm{HCl}$ and the large diffusion gradient between the nanogels and the release medium. As is evident from the release profiles, no statistical difference was observed between the native and quaternized nanogels, which demonstrates that although having a significant effect on the mucoadhesive properties of the materials, quaternization does not negatively affect the release profile of the nanogels.

\section{CONCLUSION}

In summary we have reported the facile synthesis of 'dual-functional' mucoadhesive nanogels utilizing a native PDMAEMA nanogel modified through quaternization with acryloyl chloride. From this we have concluded that the combination of static interactions and covalent-bond 
forming mucoadhesive functionalities allows for the development of materials which exhibit superior mucoadhesive properties than the native nanogels. This therefore offers a novel route to materials with superior mucoadhesive properties in a facile and cost effective manner.

\section{ACKNOWLEDGEMENTS}

The authors would like to gratefully acknowledge the Leverhulme Trust for funding (RPG2013-017). A special thanks to the Chemical Analysis Facility (CAF) at the University of Reading for access to NMR, TGA, FT-IR and TEM, to Dr Peter Harris for his help with the TEM analysis and to Dr Samuel C. Bizley, Dr Edward Mansfield and the Khutoryanskiy group for their advice throughout the work.

\section{ASSOCIATED CONTENT}

\section{Supporting Information.}

FT-IR spectra and TGA thermograms of nanogels, equations for drug loading calculations, release kinetics and statistical analysis.

\section{AUTHOR INFORMATION}

Corresponding Author

*Email: V.Khutoryanskiy@reading.ac.uk

\section{Author Contributions}


The manuscript was written through contributions of all authors. All authors have given approval to the final version of the manuscript.

\title{
Funding Sources
}

The authors would like to gratefully acknowledge the Leverhulme Trust for funding (RPG-2013017).

\author{
ABBREVIATIONS \\ DMAEMA, (2-dimethylamino)ethyl methacrylate; PDMAEMA, poly((2-dimethylamino)ethyl \\ methacrylate); PVP, poly(vinyl pyrrolidone); AIBN, azobisisobutyronitrile, MBA, N,N'- \\ methylene-bis-acrylamide;
}

\section{REFE0RENCES}

1. J. D. Smart. The basics and underlying mechanisms of mucoadhesion. Adv. Drug Delivery Rev., 2005, 57, 1556-1568.

2. C. Marriott and N. P. Gregory, Bioadhesive Drug Delivery Systems, eds. V. Lanaerts and R. Gurny, CRC Press, 1990, 1-24.

3. H. Takeuchi, H. Yamamoto and Y. Kawashima. Mucoadhesive nanoparticulate systems for peptide drug delivery. Adv. Drug Delivery Rev., 2001, 47, 39-54.

4. M. George and T. E. Abraham. Polyionic hydrocolloids for the intestinal delivery of protein drugs: Alginate and chitosan — a review. J. Controlled Release, 2006, 114, 1-14.

5. S. A. Agnihotri, N. N. Mallikarjuna and T. M. Aminabhavi. Recent advances on chitosan-based micro-and nanoparticles in drug delivery. J. Controlled Release, 2004, 100, 5-28. 
6. V. V. Khutoryanskiy. Advances in mucoadhesion and mucoadhesive polymers. Macromol. Biosci., 2011, 11, 748-764.

7. N. A. Peppas and J. J. Sahlin. Hydrogels as mucoadhesive and bioadhesive materials: a review. Biomaterials, 1996, 17, 1553-1561.

8. A. Bernkop-Schnürch. Thiomers: a new generation of mucoadhesive polymers. Adv. Drug Delivery Rev., 2005, 57, 1569-1582.

9. M. T. Cook, S. A. Schmidt, E. Lee, W. Samprasit, P. Opanasopit and V. V. Khutoryanskiy. Synthesis of mucoadhesive thiol-bearing microgels from 2(acetylthio)ethylacrylate and 2-hydroxyethylmethacrylate: novel drug delivery systems for chemotherapeutic agents to the bladder. J. Mater. Chem. B, 2015, 3, 6599-6604.

10. P. Tonglairoum, R. P. Brannigan, P. Opanasopit and V. V. Khutoryanskiy. Maleimidebearing nanogels as novel mucoadhesive materials for drug delivery. J. Mater. Chem. B, 2016, 4, 6581-6587.

11. K. Kim, K. Kim, J. H. Ryu and H. Lee. Chitosan-catechol: a polymer with long-lasting mucoadhesive properties. Biomaterials, 2015, 52, 161-170.

12. M. Davidovich-Pinhas and H. Bianco-Peled, Mucoadhesive Materials and Drug Delivery Systems, ed. V. V. Khutoryanskiy, Blackwell Science Publishing, 2014, 309-328.

13. M. Davidovich-Pinhas and H. Bianco-Peled. Novel mucoadhesive system based on sulfhydryl-acrylate interactions. J. Mater. Sci.: Mater. Med., 2010, 21, 2027-2034.

14. V. Kabanov and S. V. Vinogradov, Multifunctional Pharmaceutical Nanocarriers, ed. V. Torchilin, Springer New York, 2008, 67-80.

15. R. T. Chacko, J. Ventura, J. Zhuang and S. Thayumanavan. Polymer nanogels: a versatile nanoscopic drug delivery platform. Adv. Drug Delivery Rev., 2012, 64, 836-851. 
16. K. Raemdonck, J. Demeester and S. De Smedt. Advanced nanogel engineering for drug delivery. Soft Matter, 2009, 5, 707-715.

17. J. K. Oh, R. Drumright, D. J. Siegwart and K. Matyjaszewski. The development of microgels/nanogels for drug delivery applications. Prog. Polym. Sci., 2008, 33, 448-477.

18. H.-J. Kao, Y.-L. Lo, H.-R. Lin and S.-P. Yu. Characterization of pilocarpine-loaded chitosan/Carbopol nanoparticles. J. Pharm. Pharmacol., 2006, 58, 179-186.

19. L. Hu, L. Y. Chu, M. Yang, H. D. Wang and C. Hui Niu. Preparation and characterization of novel cationic $\mathrm{pH}$-responsive poly $\left(N, N^{\prime}\right.$-dimethylamino ethyl methacrylate) microgels. J. Colloid Interface Sci., 2007, 311, 110-117.

20. G. S. Irmukhametova, G. A. Mun and V. V. Khutoryanskiy. Thiolated mucoadhesive and PEGylated nonmucoadhesive organosilica nanoparticles from 3-mercaptopropyltrimethoxysilane. Langmuir, 2011, 27, 9551-9556.

21. H. R. Lin, K. C. Sung and W. J. Vong. In situ gelling of alginate/pluronic solutions for ophthalmic delivery of pilocarpine. Biomacromolecules, 2004, 5, 2358-2365.

22. S. Keely, A. Rullay, C. Wilson, A. Carmichael, S. Carrington, A. Corfield, D. M. Haddleton, D. J. Brayden. In vitro and ex vivo intestinal tissue models to measure mucoadhesion of poly (methacrylate) and $N$-trimethylated chitosan polymers. Pharm. Res., 2005, 22, 38-49.

23. M. H. Allen Jr., M. D. Green, H. K. Getaneh, K. M. Miller, T. E. Long. Tailoring charge density and hydrogen bonding of imidazolium copolymers for efficient gene delivery. Biomacromolecules, 2011, 12, 2243-2250. 
24. E. D. H. Mansfield, K. Sillence, P. Hole, A. C. Williams, V V. Khutoryanskiy. POZylation: a new approach to enhance nanoparticle diffusion through mucosal barriers. Nanoscale, 2015, 7, 13671-13679. 